\title{
Thiazide Intolerance - A New Zealand Perspective
}

\section{Walter Van Der Merwe*, Sergej Cicovic and Veronica van der Merwe}

North Shore Hospital, Waitemata District Health Board, Auckland, New Zealand

Thiazide diuretics were first used for the treatment of hypertension in 1957 [1] and since then have remained a cornerstone of antihypertensive therapy. It was thought they might be superseded by newer antihypertensive classes coming on-line in the 1980's and 1990's, particularly angiotensin converting enzyme inhibitors (ACE-inhibitors) and calcium channel blockers. However the ALLHAT trial [2] published in 2002, still the largest antihypertensive outcome trial ever conducted, showed that a thiazide (-like) diuretic chlorthalidone was at least as effective as an ACE-inhibitor lisinopril and a calcium channel blocker in preventing adverse cardiovascular outcomes, and in fact better in the prevention of heart failure (one of the secondary outcomes) than both other classes. On the basis of this, the primacy of thiazides in hypertension management was reaffirmed in the $7^{\text {th }}$ Report of the Joint National Committee on the Prevention, Detection, Evaluation and Treatment of Hypertension 2003 (JNC-7) [3]. This report suggested that thiazides are suitable as first-line therapy of hypertension for most, with the addition of other classes of antihypertensives as required.

Nevertheless there have always been concerns about the potentially adverse metabolic side-effects of thiazides [4-6] and whether these may obviate some of their beneficial blood pressure-lowering benefits. A more recent large trial, the ACCOMPLISH [7] showed worse cardiovascular outcomes in patients with stage 2 hypertension receiving treatment based on an ACE-inhibtor/thiazide combination than those on an ACE-inhibitor/calcium channel blocker (CCB) combination. Those results have not yet been duplicated in other trials, but some guidelines including the British (BHS/NICE 2012) [8] no longer suggest thiazides as the treatment of first choice in hypertension, even in older individuals and blacks.

Either way, thiazides remain an important component of the antihypertensive armamentarium, particularly as part of multi-drug combination therapy and a significant minority of antihypertensives are able to achieve target blood pressure without a thiazide as part of their regimen.

Despite their widespread utilisation, metabolic side effects are common with thiazides. Hypokalaemia is very common $[9,10]$ but usually manageable with potassium supplementation or combination with potassium-sparing drugs and does not usually mandate thiazide cessation. Hyponatraemia, by contrast, is also relatively common, occasionally life-threatening, and is also much more difficult to treat [11]. Unless very mild it usually necessitates permanent withdrawal of thiazide therapy [12].

We wished to audit our use of thiazide diuretics in the hypertension clinic to determine the extent and nature thiazide intolerance, with particular reference to hyponatraemia.

\section{Method}

Patients are referred to the Waitemata Hypertension Clinic for difficult or resistant hypertension, usually by general practitioners. They are discharged back to the referrer once blood pressure target is achieved, or failing that, the patient has achieved the best blood pressure achievable for them.

Patients discharged from the Waitemata Hypertension Clinic over a 30-month period (1 March 2009 - 30 September 2012) were audited for thiazide use and intolerance.

The thiazide drugs available in New Zealand are hydrochlorothiazide, bendrofluazide, indapamide, and chlorthalidone. Chlorthalidone is not technically a thiazide, as it has a different molecule. It is referred to as a "thiazide-like" diuretic and is generally considered alongside the conventional thiazides [13].

We define hyponatraemia as a plasma sodium $<135 \mathrm{mmol} / \mathrm{l}$, but in the absence of symptoms will usually tolerate a plasma sodium down to $130 \mathrm{mmol} / \mathrm{l}$. Below that we generally discontinue thiazide medication.

\section{Results}

Between 1 March 2009 and 30 September 2012, 783 consecutive new referrals with difficult or resistant hypertension were discharged from the Waitemata hypertension clinic. Of these 701 were discharged on $>=1$ antihypertensive medications. (The remainder were determined not to warrant antihypertensive drug therapy at the present time).

Of those discharged on antihypertensive medication, mean BP at first visit was $155 / 87$ on a mean of 2.6 antihypertensive drugs. After a mean of 3 visits, the 701 pts discharged on any antihypertensive medication had a mean BP of 130/75 and were taking a mean of 2.9 antihypertensive drugs.

Of those discharged on drugs 380/701 (54\%), had been prescribed a thiazide at some time (either previously, or initiated at the hypertension clinic), but $99 / 701$ (14\%) had proven thiazide-intolerant, so that 281/701 (40\%) were discharged on a thiazide.

The recorded causes of thiazide intolerance were hyponatraemia (37), "not specified" (24), nausea and excessive urination (7), dizziness (6), erectile dysfunction (5), hypokalaemia (4), rash (4). All of the "not specified" group were those who were referred to the clinic with a preexisting history of thiazide intolerance, but where no further details were provide or obtainable.

The thiazides involved in the 37 who developed hyponatraemia were bendrofluazide (15 cases, average dose $2.5 \mathrm{mg}$ daily), hydrochlorothiazide (11 cases, average dose $31 \mathrm{mg}$ daily), chlorthalidone ( 9 cases, average dose $19.4 \mathrm{mg}$ daily), and indapamide ( 2 cases, average dose $2.5 \mathrm{mg}$ daily). Of the 37 cases, 32 were concurrently on an ACE-inhibitor or angiotensin receptor blocker when they developed hyponatraemia, 4 were on amiloride (average dose $5 \mathrm{mg}$ daily) and 1 was on spironolactone ( $25 \mathrm{mg}$ daily)

*Corresponding author: Walter van der Merwe, North Shore Hospital, Waitemata District Health Board, Auckland, New Zealand, Tel: (09) 9181666 E-mail: walter.vandermerwe@waitematadhb.govt.nz

Received January 10, 2014; Accepted January 28, 2014; Published January 30 2014

Citation: Merwe WVD, Cicovic S, van der Merwe V (2014) Thiazide Intolerance - A New Zealand Perspective. J Hypertens 3: 136. doi:10.4172/2167-1095.1000136

Copyright: @ 2014 Merwe WVD, et al. This is an open-access article distributed under the terms of the Creative Commons Attribution License, which permits unrestricted use, distribution, and reproduction in any medium, provided the original author and source are credited. 
Citation: Merwe WVD, Cicovic S, van der Merwe V (2014) Thiazide Intolerance - A New Zealand Perspective. J Hypertens 3: 136. doi:10.4172/21671095.1000136

Page 2 of 2

\begin{tabular}{|l|c|c|c|c|}
\hline & Discharged on thiazide (281) & Thiazide intolerant (99) & $\begin{array}{c}\text { Thiazide intolerant due to } \\
\text { hyponatraemia (37) }\end{array}$ & $\begin{array}{c}\text { Thiazide intolerance other than hyponatraemia } \\
\text { (including “not specified") (62) }\end{array}$ \\
\hline Gender (M/F) & $123 / 158$ & $22 / 77$ & $6 / 31$ \\
\hline BMI & 30.9 & 27 & 25 & $16 / 46$ \\
\hline Age & 61 & 66 & 73 & 28 \\
\hline
\end{tabular}

Table 1: The characteristics of patients discharged on, and intolerant of thiazides

The characteristics of patients discharged on, and intolerant of, thiazides are listed in Table 1. Those intolerant of thiazides are separated in to those due to hyponatraemia and all other causes.

There were significant associations of thiazide intolerance with age, gender, BMI, and also with concurrent ACE-inhibitor on angiotensin receptor blocker therapy (32/37 patients) which has been reported as an important risk-factor for thiazide-hyponatraemia [14].

Of those discharged on a thiazide, females made up 56\%, average age was 61 , and average BMI 30.9 .

Of those intolerant of thiazides specifically due to hyponatraemia, 83\% (31) were female, average age was 73 and average BMI 25.

Of those intolerant of thiazide due to "other" causes, the parameters of gender ( $74 \%$ female), age (average 62), and BMI (average 28) lay between those of thiazide-tolerant patients and thiazide-intolerant due to hyponatraemia. This perhaps suggests that a significant number of the "not specified" intolerance was hyponatraemia-related and that if these were removed, the baseline characteristics of patients intolerant of thiazides due to factors other than hyponatraemia (rash, nausea, erectile dysfunction etc) would not differ significantly from controls.

\section{Summary}

Thiazides remain an important component of the antihypertensive drug armamentarium, and are often indispensible as part of combination therapy in more severe forms of hypertension. However, they need to be used with due care, with particular attention to hyponatraemia, a potentially life-threatening complication.

In this series, among 701 consecutive hypertension clinic patients discharged on $>=1$ drug, 380 (54\%) had been started on a thiazide diuretic, with $281(40 \%)$ remaining on a thiazide at discharge. Of the $99(26 \%)$ who were thiazide-intolerant, $37(10 \%)$ were intolerant due to hyponatraemia. It is likely that this number would be higher if all old information for the "not specified" group was available.

\section{Discussion}

Our data confirm what other groups have shown, that thiazideinduced hyponatraemia is a disease predominantly affecting older women with low body weight. Thiazide doses in affected patients were not particularly high, but there did seem to be a strong association with concurrent ACE-inhibitor or angiotensin receptor blocker treatment.

It is essential that patients commencing thiazide treatment, particularly those in this demographic, are aware of the risk and report any suggestive symptoms immediately (headache, weakness, confusion, seizures etc).

It is also mandatory to check renal function and electrolytes within 2-3 weeks of commencing therapy, and again after any increase in dose. Particular vigilance may also be warranted where thiazides are prescribed together with ACE-inhibitors or angiotensin receptor blockers. Patients should also be cautioned to temporarily discontinue thiazides if they are unwell and at risk of hypovolaemia (diarrhoea, vomiting etc).

\section{References}

1. Novello FC, Sprague JM (1957) Benzothiadiazine dioxides as novel diuretics. J Am Chem Soc 79: 2028-2029.

2. ALLHAT research Collaborative Group. Antihypertensive and Lipid-Lowering Treatment to Prevent Heart Attack Trial. JAMA.

3. Chobanian AV, Bakris GL, Black HR, Cushman WC, Green LA, et al. (2003) The Seventh Report of the Joint National Committee on Prevention, Detection, Evaluation, and Treatment of High Blood Pressure. Hypertension 42: 12061252.

4. Wing LM, Reid CM, Ryan P, Beilin LJ, Brown MA, et al. (2003) A comparison of outcomes with angiotensin-converting--enzyme inhibitors and diuretics for hypertension in the elderly. N Engl J Med 348: 583-592.

5. Reungjui S, Hu H, Mu W, Roncal CA, Croker BP, et al. (2007) Thiazide-induced subtle renal injury not observed in states of equivalent hypokalemia. Kidney Int 72: $1483-1492$.

6. Reungjui S, Roncal CA, Mu W, Srinivas TR, Sirivongs D, et al. (2007) Thiazide diuretics exacerbate fructose-induced metabolic syndrome. J Am Soc Nephrol 18: $2724-2731$.

7. Jamerson K, Weber MA, Bakris GL, Dahlöf B, Pitt B, et al. (2008) Benazepril plus amlodipine or hydrochlorothiazide for hypertension in high-risk patients. $\mathrm{N}$ Engl J Med 359: 2417-2428.

8. NICE guidelines group (2011) CG127 Hypertension: Clinical management of primary hypertension in adults.

9. Siegel D, Hulley SB, Black DM, Cheitlin MD, Sebastian A, et al. (1992) Diuretics, serum and intracellular electrolyte levels, and ventricular arrhythmias in hypertensive men. JAMA 267: 1083-1089.

10. Greenberg A (2000) Diuretic complications. Am J Med Sci 319: 10-24

11. Hoorn EJ, Lindemans J, Zietse R (2006) Development of severe hyponatraemia in hospitalized patients: treatment-related risk factors and inadequate management. Nephrol Dial Transplant 21: 70-76.

12. Chow KM, Szeto CC, Wong TY, Leung CB, Li PK (2003) Risk factors for thiazide-induced hyponatraemia. QJM 96: 911-917.

13. Carter BL, Ernst ME, Cohen JD (2004) Hydrochlorothiazide versus chlorthalidone: evidence supporting their interchangeability. Hypertension 43 : 4-9.

14. Rastogi D, Pelter MA, Deamer RL (2012) Evaluations of hospitalization associated with thiazide-associated hyponatremia. J Clin Hypertens (Greenwich) 14: 158-164 